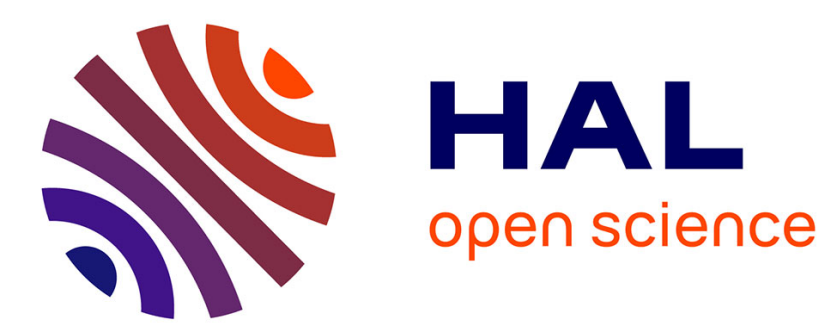

\title{
Axiomatics of level structure values
}

Frederic Chantreuil

\section{To cite this version:}

Frederic Chantreuil. Axiomatics of level structure values. [University works] auto-saisine. 1998, 15 p. hal-01594115

\section{HAL Id: hal-01594115 \\ https://hal.science/hal-01594115}

Submitted on 26 Sep 2017

HAL is a multi-disciplinary open access archive for the deposit and dissemination of scientific research documents, whether they are published or not. The documents may come from teaching and research institutions in France or abroad, or from public or private research centers.
L'archive ouverte pluridisciplinaire HAL, est destinée au dépôt et à la diffusion de documents scientifiques de niveau recherche, publiés ou non, émanant des établissements d'enseignement et de recherche français ou étrangers, des laboratoires publics ou privés.

\section{(1)}

Distributed under a Creative Commons Attribution - NonCommercial - NoDerivatives| 4.0 


\section{INST ITUT NATIONAL \\ DE LA RECHERCHEAGRONOMIQUE}

AXIOMATICS OF LEVEL STRUCTURE VALUES

Frédéric CHANTREUIL

Cahier $\mathbf{n}^{\circ}$ 98/01

Mars 1998

ECONOMIE

ET SOCIOLOGIE RURALES

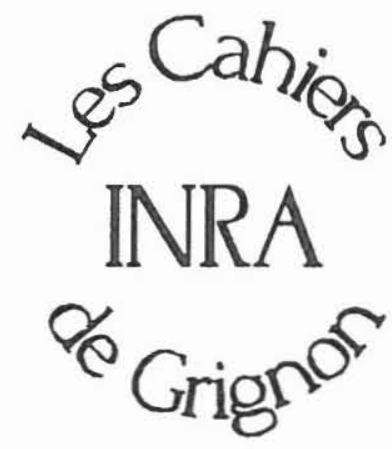

INRA - Station d'Economie et Sociologie Rurales

78850 Grignon

Tél. (1) 30.81.53.30 Fax (1) 30.81.53.68 


\begin{abstract}
In this paper we develop six values for side payments games when a cooperative description of the players is a priori given. This cooperation description, called a level structure, is made of a sequence of coalition structures. Those values are extensions of values such as the Shapley value (1953), Owen's value (1977) and Winter's level structure value (1989).
\end{abstract}

KEY WORDS : LEVEL STRUCTURE, VALUE OF TU-GAMES.

VALEURS DE JEUX COOPERATIFS A STRUCTURES COALITIONNELLES

Résumé

Dans cet article, nous proposons six valeurs de jeux coopératifs lorsque les joueurs sont a priori organisés en une suite de structures coalitionnelles. Ces valeurs sont des extensions de valeurs telles que la valeur de Shapley (1953), la valeur d'Owen (1977) et la valeur de Winter (1989).

MOTS CLES : STRUCTURE COALITIONNELLE, VALEUR DE JEUX COOPERATIFS 


\title{
AXIOMATICS OF LEVEL STRUCTURE VALUES
}

\author{
F. Chantreuil ${ }^{1}$ \\ INRA-ESR Grignon, BP.1, 78850 Thiverval-Grignon, France
}

\begin{abstract}
In this paper we develop six values for side payments games when a cooperation description of the players is a priori given. This cooperation description, called a level structure, is made of a sequence of coalition structures. Those values are extensions of values such as the Shapley value (1953), Owen's value (1977) and Winter's level structure value (1989).
\end{abstract}

\section{Introduction}

In this paper we develop six values for side payments games which take into account the possibility that some players may be more likely to act together than others. Actually, in many situations a coalition structure is not an adequate description of the cooperation structure and a more detailed description of the different levels of cooperative agreements is needed. To account for all possible links among the players we can extend the notion of coalition structure value to games in which the players are already organized into a level structure (LS), that is a sequence of coalition structures.

Consider a characteristic function game $U$ with a set of players $N=\{1,2,3,4,5,6,7\}$ and suppose that these players are organized into two coalitions, say $A=\{1,2,3\}$ and $B=\{4,5,6,7\}$ and into parties within each coalition, say $C=\{1,2\}, D=\{3\}$, $E=\{4,5\}$ and $F=\{6,7\}$. In other words, the players are organized into a level structure (figure 1) $\mathbf{B}=\left\{\mathcal{B}^{1}, \mathcal{B}^{2}\right\}$, with $\mathcal{B}^{1}=\{A, B\}$ the first level of cooperation and $\mathcal{B}^{2}=\{C, D, E, F\}$ the second one.

${ }^{1}$ I thank Guillermo Owen and Jean-François Laslier for helpful discussions and comments, and Dirk van de gaer for his valuable remarks. The usual caveat applies 


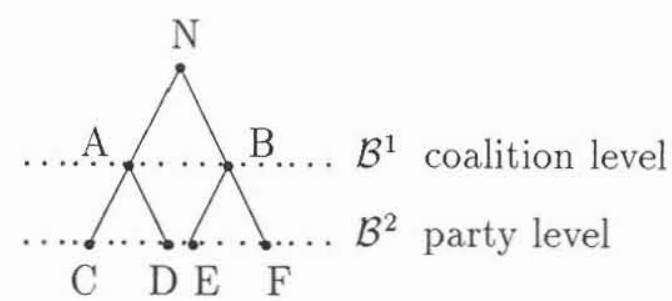

Figure 1

Our purpose is to determine the final repartition of the total amount $U(N)$ among the players. If we suppose that the level structure is a priori given, we might expect that each coalition $(A$ and $B$ ) will choose a delegate to represent the coalition in a bargaining situation whose formal representation is the quotient game $V$, which is a two-person side payments game. So, a reasonnable expectation for coalition $A$ (resp. $B$ ) is the amount $\varphi_{A}(V)$ (resp. $\varphi_{B}(V)$ ) which would normally be expected by player $A$ (resp. $B$ ) in game $V$ (where $\varphi$ denotes the Shapley value). Then, the members of $A$, e.g, would bargain among themselves to determine the division of the amount $\varphi_{A}(V)$ which the coalition receives. Again, we might expect that each partie $(C$ and $D)$ will choose a delegate to represent the party in a bargaining situation whose formal representation is the subgame $W_{A}$ defined on the coalition $A$. This subgame is a two-person side payments game. So, the amount which would normally be expected by player $C$ (resp. $D$ ) is the Shapley value of player $C$ (resp. $D$ ) in subgame $W_{A}$, i.e $\varphi_{C}\left(W_{A}\right)$ (resp. $\varphi_{D}\left(W_{A}\right)$ ). Finally, player $i \in C$ should expect to receive a fraction equal to $\varphi_{i}\left(W_{C}\right)$ which is the Shapley value of player $i$ in subgame $W_{C}$ defined on the party $C$. Thus, an expectation for player $i \in C \subset A$ in game $U$, assuming the level structure $\mathbf{B}$, is the product of the Shapley values in the respective subgames and quotient game.

This example gives a simple illustration of the way we proceed to determine the final payoff for each player. At the first level of the level structure, the coalitions bargain among themselves to determine the division of the total amount $U(N)$. At the second level, the parties belonging to the same coalition bargain among themselves to determine the division of the amount the coalition receives. Finally, the players of a party divide among themselves the amount the party receives. This final distribution of payoff reflect the fact that the players are already organized into a level structure.

Obviously, the value of player $i \in C \subset A$ depends crucially on the definition of the subgames $W_{C}$ and $W_{A}$ and on the defintion of the quotient game $V$. In section 3 , we propose three level structure values based on a bargaining procedure among coalitions and three different bargaining procedures within coalitions. In section 4, we propose three other level structure values by changing the bargaining procedure among coalitions.

\section{Notations and definitions}

We consider a side payments game $U$ with a set of players $N=\{1, \ldots, n\}$ and $P(N)$ the set of all finite partitions of $N$, where a finite partition, $\mathcal{B}^{c}$, is a set of coalitions 
$B_{j c}$ such that

$$
\begin{aligned}
& \mathcal{B}^{c}=\left\{B_{1^{c}}, \ldots, B_{j^{c}}, \ldots, B_{m^{c}}\right\}, M^{c}=\left\{1^{c}, \ldots, m^{c}\right\} \\
& \bigcup_{j^{c}=1^{c}}^{m^{c}} B_{j^{c}}=N \text { and } B_{q^{c}} \bigcap B_{k^{c}}=\emptyset, q^{c} \neq k^{c} \in M^{c}
\end{aligned}
$$

where $\mathcal{B}^{c}$ represents the $\mathrm{c}$-th level of cooperation.

\section{Definition 1}

We define a binary relation $\unlhd$ on $P(N)$, where $\mathcal{B}^{c} \unlhd \mathcal{B}^{h}$ means that the finite partition $\mathcal{B}^{h}$ is identical to $\mathcal{B}^{c}$ or finer than $\mathcal{B}^{c}$. This binary relation is a quasi-ordering on $P(N)$.

\section{Definition 2}

A level structure (LS) $\mathbf{B}$ is a subset of $P(N)$ such that the binary relation $\unlhd$ is complete on $\mathbf{B}$.

\section{Definition 3}

A LS $\mathbf{B}=\left(\mathcal{B}^{1}, \ldots, \mathcal{B}^{c}, \ldots, \mathcal{B}^{g}\right)$ is said to be strict if and only if for all $c=1, \ldots, g-1, \mathcal{B}^{c} \triangleleft$ $\mathcal{B}^{c+1}$, where $\triangleleft$ is the asymmetric component of $\unlhd$.

\section{Definition 4}

For all coalitions $B_{j^{c}} \in \mathcal{B}^{c}$, we note $n\left(B_{j^{c}}\right)=\sharp\left\{B_{j^{c+1}} \in \mathcal{B}^{c+1}: B_{j^{c+1}} \subseteq B_{j^{c}}\right\}$, for all $\mathrm{c}=1, \ldots, \mathrm{g}-1$.

\section{Definition 5}

For every coalition $B_{j^{c}} \in \mathcal{B}^{c}$, if $n\left(B_{j c}\right)=1$, that is if there exists only one coalition $B_{j^{c+1}} \in \mathcal{B}^{c+1}$ such that $B_{j^{c+1}}=B_{j^{c}}$, then we say that $B_{j^{c}}$ is a strong coalition for $\left(\mathcal{B}^{c}, \mathcal{B}^{c+1}\right)$.

To determine the level structure values we always consider a side payments game with a set of players organized into a strict level structure $\mathbf{B}=\left\{\mathcal{B}^{1}, \mathcal{B}^{2}\right\}$. So, the players are put into coalitions and into parties within each coalition.

\section{Definition 6}

Let $\Pi(N)$ the set of all permutations of the set of players, then

(i) For all $\pi \in \Pi(N), \pi$ is a symmetry of $U$ if and only if, for all $S \subseteq N, \pi U(S)=$ $U\left(\pi S^{\prime}\right)$

(ii) For all $\pi \in \Pi(N), \pi$ is a symmetry of $\mathbf{B}$ if and only if, for all $S \subseteq N, S \subseteq$ $B_{j^{2}}, \pi(S) \subseteq B_{j^{2}}$ and, for all $S \subseteq N, S \subseteq B_{j^{1}}, \pi(S) \subseteq B_{j^{1}}$ 


\section{Definition 7}

A Level Structure Value (LSV), $\varphi^{2}$, is a function which assigns to each pair $(U ; \mathbf{B})$, a vector containing the payoffs of each of the $n$ players.

$\varphi^{2}$ is the LSV in a two level game which derives from the Shapley value $\varphi$. This function satisfies the following five axioms.

We define a carrier as in Shapley's paper, and let $\pi$ and $\rho^{c}$ denote permutations of $\mathrm{N}$ and $M^{\mathrm{c}}(\mathrm{c}=1,2)$ respectively. The game $\pi U$ is define by $\pi U(S)=U(\pi S)$.

Axiom 1 (Efficiency)

For any carrier $\mathrm{H}$ of $\mathrm{U}, \sum_{i \in H} \varphi_{i}^{2}(U ; \mathbf{B})=U(H)$

Axiom 2 (Anonymity)

For any $\pi \in \Pi(N)$, if $\pi$ is a symmetry of $(U ; \mathbf{B})$, then $\varphi_{i}^{2}(\pi(U ; \mathbf{B}))=\varphi_{(\pi i)}^{2}(U ; \mathbf{B})$

Axiom 3 (Independence)

For any $B_{j^{1}} \in \mathcal{B}^{1}$, the quantity $\sum_{i \in B_{j^{1}}} \varphi_{i}^{2}(U ; \mathbf{B})$ depends only on the bargaining procedure among coalitions.

For any $B_{j^{2}} \in \mathcal{B}^{2}$, the quantity $\sum_{i \in B_{j^{2}}} \varphi_{i}^{2}(U ; \mathbf{B})$ depends only on the bargaining procedure within coalitions.

Axiom 4 (Symmetry)

If $i$ and $h$ are two symmetric players in the subgame $W_{B_{j^{2}}}$, then $\varphi_{i}^{2}(U ; \mathbf{B})=\varphi_{h}^{2}(U ; \mathbf{B})$ If $B_{j^{2}}$ and $B_{q^{2}}$ are two symmetric coalitions in the subgame $W_{B_{j^{1}}}$, then $\varphi_{B_{j^{2}}}^{2}(U ; \mathbf{B})=$ $\varphi_{B_{q^{2}}}^{2}(U ; \mathbf{B})$

If $B_{j^{1}}$ and $B_{q^{1}}$ are two symmetric coalitions in the quotient game $V$, then $\varphi_{B_{j^{1}}^{2}}(U ; \mathbf{B})=$ $\varphi_{B_{q^{1}}^{2}}(U ; \mathbf{B})$

Axiom 5 (Additivity)

$\varphi^{2}(U ; \mathbf{B})+\varphi^{2}(V ; \mathbf{B})=\varphi^{2}(U+V ; \mathbf{B})$

The first axiom, usually called the carrier axiom, requires that the sum of LSV values over all players $i$ in any carrier $H$ equals $U(N)$. Since this must hold for any carrier, it implies that the LSV value of player $i$ equal zero if $i$ is a null player. The second axiom requires that the LSV value depends on the strict LS $\mathbf{B}$, but not on the labelling of the unions and the players. The third axiom is an independance condition. It requires that the sum of LSV values over all players $i \in B_{j^{1}}$ equals the Shapley value of player $B_{j^{1}}$ in game $V$, and that the sum of LSV values over all players $i \in B_{j^{2}}$ equals the Shapley value of player $B_{j^{2}}$ in game $W_{j^{1}}$. The fourth axiom is an axiom of symmetry among the players. It requires that two players or two coalitions who are identically treated by the characteristic function of the games representing the bargaining procedure among coalitions and within coalitions must be identically treated by the LSV value. The fifth axiom, called the additivity axiom, specifies how the LSV of different games must be related to one another.

3. Level structure values with a simple quotient game

If we suppose that in each coalition $B_{j^{1}} \in \mathcal{B}^{1}$ an individual (a delegate) is selected to represent the coalition, then it can be said that the problem of the division of the 
gain among the coalitions of the first finite partition of $N$ is a bargaining situation, formally representated by the quotient game $V=U / \mathcal{B}^{1} . V$ is a game with a set of players $M^{1}=\left\{1^{1}, \ldots, j^{1}, \ldots, m^{1}\right\}$ and is given by :

$$
V(S)=U\left(\bigcup_{B_{j^{1}} \in S} B_{j^{1}}\right), \text { for any } S \in \mathcal{B}^{1}
$$

Thus a reasonnable expectation for the $j^{\text {th }}$ coalition is the amount $\varphi_{B_{j^{1}}}(V)$, which is the Shapley value of player $B_{j^{1}}$ in game $\mathrm{V}$ and would be normally expected by this player.

Then, the members of this coalition $B_{j^{1}}$ would bargain among themselves to determine the division of the quantity the coalition receives. These members are the coalitions of the finite partition $\mathcal{B}^{2}$ which belong to the coalition $B_{j^{1}}$. Note that we also suppose that in each coalition $B_{j^{2}}$ a selected delegate represents the coalition.

As we argue in the previous example, the division of the quantity the coalition receives depends on the definition of the subgame we can defined on this specific coalition. Considering the example given in introduction, the first bargainning procedure within coalitions we consider as the following interpretation. Parties $C$ and $D$ have two pieces of information. They know that they have to divide the amount the coalition $A$ receives among themselves and they know the amount they can obtain on their own in the characteristic function game $U$.

Hence, this bargaining procedure within coalitions originates when we simply take into account the amount $U(K)$ that every $K \subset B_{j^{1}}, K \in \mathcal{B}^{2}$ can obtain itself. To do this, we can define the subgame $W_{B_{j^{1}}}$ on coalition $B_{j^{1}}$ :

$$
\begin{gathered}
W_{B_{j^{1}}}(\emptyset)=0 \\
W_{B_{j^{1}}}(K)=U(K), \text { for all } K \subset B_{j^{1}}, K \in \mathcal{B}^{2} \\
W_{B_{j^{1}}}\left(B_{j^{1}}\right)=\varphi_{B_{j^{1}}}(V)
\end{gathered}
$$

Then, a reasonable expectation for coalition $B_{j^{2}} \subset B_{j^{1}}$ is the amount $\varphi_{B_{j^{2}}}\left(W_{B_{j^{1}}}\right)$, which is the Shapley value of player $B_{j^{2}}$ in the subgame $W_{B_{j^{1}}}$.

To determine the division of the amount $\varphi_{B_{j^{2}}}\left(W_{B_{1^{1}}}\right)$ among the members of the party $B_{j^{2}}$, we use the same argument. We define the subgame $W_{B_{j^{2}}}$ on party $B_{j^{2}}$ so as to take into account the individual possibilities of each $H \subset B_{j^{2}}$ :

$$
\begin{gathered}
W_{B_{j^{2}}}(\emptyset)=0 \\
W_{B_{j^{2}}}(H)=U(H), \text { for all } H \subset B_{j^{2}} \\
W_{B_{j^{2}}}\left(B_{j^{1}}\right)=\varphi_{B_{j^{2}}}\left(W_{B_{j^{1}}}\right)
\end{gathered}
$$

Thus, each player $i \in B_{j^{2}} \subset B_{j^{1}}$ can obtain the amount $\varphi_{i}\left(W_{B_{j^{2}}}\right)$, which is the Shapley value of player $i$ in the subgame $W_{B_{j^{2}}}$.

This bargaining procedure within coalitions can be characterized by the following axiom. 


\section{Axiom 6}

For all $K \subset B_{j^{1}}, W_{B_{j^{1}}}(K)=U(K)$ and $W_{B_{j^{1}}}\left(B_{j^{1}}\right)=\varphi_{B_{j^{1}}}(V)$

For all $H \subset B_{j^{2}}, W_{B_{j^{2}}}(H)=U(H)$ and $W_{B_{j^{2}}}\left(B_{j^{2}}\right)=\varphi_{B_{j^{2}}}\left(W_{B_{j^{1}}}\right)$

This axiom implies that the characteristic function of the subgame $W_{B_{j 1}}$, is determined by giving to all $K \subset B_{j^{1}}$ the corresponding value of the characteristic function of game $U$, and to the coalition $B_{j^{1}}$ the amount which this coalition receives, that is the Shapley value of player $B_{j^{1}}$ in the quotient game $V$. By the same token, the characteristic function of the subgame $W_{B_{j^{2}}}$, is determined by giving to all $H \subset B_{j^{2}}$ the corresponding value of the characteristic function of game $U$, and to the coalition $B_{j^{2}}$ the amount which this coalition receives, that is the Shapley value of player $B_{j^{2}}$ in the subgame $W_{B_{j^{1}}}$

\section{Theorem 1}

There exists a unique LSV $\varphi^{2}$ satisfying axioms 1-6 for side payments games with a strict LS B. It is given by ${ }^{2}$

$$
\begin{aligned}
\varphi_{i}^{2}(U ; \mathbf{B})= & \sum_{\substack{H \subset B_{j}^{2} \\
i \notin H}} \delta_{h}\left(b_{j}^{2}\right)[U(H \bigcup\{i\})-U(H)]+\frac{1}{b_{j}^{2}} \\
& {\left[\sum_{\substack{G \subset B_{j}^{1} \\
B_{j}^{2} \notin G}} \delta_{g}\left(n\left(B_{j}^{1}\right)\right)\left[U\left(G \bigcup B_{j}^{2}\right)-U(G)\right]-U\left(B_{j}^{2}\right)\right.} \\
& \left.+\frac{1}{n\left(B_{j}^{1}\right)}\left[\sum_{\substack{S \subset M^{1} \\
B_{j}^{1} \notin S}} \delta_{s}\left(m^{1}\right)\left[U\left(S \bigcup B_{j}^{1}\right)-U(S)\right]-U\left(B_{j}^{1}\right)\right]\right]
\end{aligned}
$$

Return to our example given in introduction, we can consider another interpretation for the bargainning procedure within coalitions. This interpretation is as follow. Parties $C$ and $D$ have not two but three pieces of information. They know that they have to divide the amount the coalition $A$ receives among themselves, they know the amount they can obtain on their own in the characteristic function game $U$ and they know that the amount they have to divide among themselves is the result of negociations between coalitions $A$ and $B$.

Then, the second bargaining procedure within coalitions consists in accounting for the amount $U(K)$ that every $K \subset B_{j^{1}}, K \in \mathcal{B}^{2}$ can obtain itself and the amounts $U\left(K \cup B_{q^{1}} \cup \ldots \cup B_{h^{1}}\right)$ that $K$ could obtain if he would defect from coalition $B_{j^{1}}$ and form a new coalition with one or more of the remaining coalitions of $\mathcal{B}^{1}$. Remark

\footnotetext{
${ }^{2}$ The heuristic determination of the LSV and the proof of theorem 1 are given in appendix
} 
that $\mathbf{B}$ is not supposed to change. The construction only serves to compute the relative payoff of each member of the coaliton $B_{j^{1}}$.

For any $K \subseteq B_{j^{1}}$, and $K^{\prime}$ its complement relative to $B_{j^{1}}$, we define a restricted game $V_{B_{j^{1}} / K}$ as representing the quotient game $V$ when $K$ replaces the coalition $B_{j^{1}}$ in the finite partition $\mathcal{B}^{1} . V_{B_{j^{1}} / K}$ is a game with a set of players $M^{1} \mid B_{j^{1}} / K$ and is given by :

$$
V_{B_{j^{1}} / K}(S)=U\left(\bigcup_{B_{q^{1}} \in S} B_{q^{1}}-K^{\prime}\right), \text { for all } S \subseteq M^{1}
$$

Then a reasonable expectation for $K$ in the restricted game $V_{B_{j^{1}} / K}$ is the amount $\varphi_{K_{1}}\left(V_{B_{j^{1}} / K_{1}}\right)$ which is the Shapley value of player $K$ in this restricted game. This amount also represents the relative payoff, in game $U$, of $K$ if he would defect from the coalition $B_{j^{1}}$.

Using the measure of the relative payoff of each member of the coalition $B_{j^{1}}$, we can define the subgame $W_{B_{j^{1}}}$ on the coalition $B_{j^{1}}$ by :

$$
\begin{gathered}
W_{B_{j^{1}}}(\emptyset)=0 \\
W_{B_{j^{1}}}(K)=\varphi_{K}\left(V_{B_{j^{1}} / K}\right), \text { for all } K \subseteq B_{j^{1}}
\end{gathered}
$$

Thus each $B_{j^{2}} \subseteq B_{j^{1}}$ can obtain the amount $\varphi_{B_{j^{2}}}\left(W_{B_{j^{1}}}\right)$ which is the Shapley value of player $B_{j^{2}}$ in the subgame $W_{B_{j^{1}}}$.

Then we have to determine the division of the amount the coalition $B_{j^{2}}$ receives among its members. We can repeat this procedure to define the restricted game $W_{B_{j^{1}} / H}$ as representing the subgame $W_{B_{j^{1}}}$ when $H \subseteq B_{j^{2}}$ replaces the coalition $B_{j^{2}}$ in the finite partition $\mathcal{B}^{2}$. So the relative payoff of $H$ if he would defect from $B_{j^{2}}$ is given by the Shapley value of player $H$ in this restricted game. Then we define the subgame $W_{B_{j^{2}}}$ on the coalition $B_{j^{2}}$ by :

$$
\begin{gathered}
W_{B_{j^{2}}}(\emptyset)=0 \\
W_{B_{j^{2}}}(H)=\varphi_{H}\left(W_{B_{j^{1}} / H}\right) \text {, for all } H \subseteq B_{j^{2}}
\end{gathered}
$$

Thus each $i \in B_{j^{2}}$ can obtain the amount $\varphi_{i}\left(W_{B_{j^{2}}}\right)$ which is the Shapley value of player $i$ in this subgame.

This bargaining procedure within coalitions can be characterized by the following axiom.

\section{Axiom 6',}

For all $K \subseteq B_{j^{1}}, K \in \mathcal{B}^{2}, W_{B_{j^{1}}}(K)=\varphi_{K}\left(V_{B_{j^{1}} / K}\right)$

For all $H \subseteq B_{j^{2}}, W_{B_{j^{2}}}(H)=\varphi_{H}\left(W_{B_{j^{1}} \mid B_{j^{2}} / H}\right)$

This axiom implies that the characteristic function of the subgame $W_{B_{j^{1}}}$, is determined by giving to all $K \subseteq B_{j^{1}}$ the Shapley value of player $K$ in the restricted quotient game $V_{B_{j 1} / K}$. Furthermore, the characteristic function of the subgame 
$W_{B_{j^{2}}}$, is determined by giving to all $H \subseteq B_{j^{2}}$ the Shapley value of player $H$ in the restreint subgame $W_{B_{j^{1}} \mid B_{j^{2}} / H}$.

\section{Theorem 2}

There exists a unique LSV $\varphi^{2}$ satisfying axioms 1-5 and 6' for side payments games with a strict LS $\mathbf{B}$; it is given by the formula ${ }^{3}$

$$
\begin{gathered}
\varphi_{i}^{2}(U ; \mathbf{B})=\sum_{\substack{S \subset M^{1} \\
B_{j^{1}} \notin S}} \sum_{\substack{\text { S } \\
B_{j^{2}} \notin K}} \sum_{\substack{H \subset B_{j^{2}} \\
i \notin H}} \frac{s !\left(m^{1}-k-1\right) ! k !\left[n\left(B_{j^{1}}\right)-k-1\right] ! h !\left(b_{j^{2}}-h-1\right)}{m^{1} ! n\left(B_{j^{1}}\right) ! b_{j^{2}} !} \\
{[U(S \bigcup K \bigcup H \bigcup\{i\})-U(S \bigcup K \bigcup H)]}
\end{gathered}
$$

Return to our example, the last bargaining procedure within coalitions we consider has the following interpretation. Parties $C$ and $D$ have more information. They know that the coalition $B$ is decomposed into two parties, $E$ and $F$.

Thus, the third bargaining procedure within caolitions arizes when we take into account not only the amount $U\left(K_{1}\right)$ that every $K_{1} \subset B_{j^{1}}, K \in \mathcal{B}^{2}$ can obtain itself but also the amounts $U\left(K_{1} \cup B_{q^{1}} \cup \ldots B_{h^{1}} \cup \ldots \cup B_{q^{2}} \cup \ldots \cup B_{h^{2}}\right)$ which he could obtain if he would defect from coalition $B_{j^{1}}$ and form a new coalition with one or more of the remaining coalitions of $\mathcal{B}^{2}$. So, for all $K \subset B_{j^{1}}, K \in \mathcal{B}^{2}$, and $K^{\prime}$ its complement relative to $B_{j^{1}}$, we define the game $V_{\mathcal{B}^{2} \mid B_{j^{1}} / K}$ on the coalition structure $\mathcal{B}^{2}$ when $K$ replaces all the parties $B_{j^{2}}$ belonging to the coalition $B_{j^{1}}$. Thus, $V_{\mathcal{B}^{2} \mid B_{j^{1}} / K}$ is a game with $m^{2}-n\left(B_{j^{1}}\right)+1$ players, and we have :

$$
V_{\mathcal{B}^{2} \mid B_{j^{1}} / K}(G)=U\left(\underset{B_{q^{2} \in G}}{\bigcup} B_{q^{2}}\right), \text { for all } G \in M^{2} \mid B_{j^{1}} / K
$$

Then a reasonable expectation for player $K$ if he replaces $B_{j^{1}}$ is the amount $\varphi_{K}\left(V_{\mathcal{B}^{2} \mid B_{j^{1}} / K}\right)$, which is the Shapley value of player $K$ in the game $V_{\mathcal{B}^{2} \mid B_{j 1} / K}$.

Using the relative payoff of each subset of $B_{j^{1}}$, we can define the subgame $W_{B_{j^{1}}}$ on coalition $B_{j^{1}}$ :

$$
\begin{gathered}
W_{B_{j^{1}}}(\emptyset)=0 \\
W_{B_{j^{1}}}(K)=\varphi_{K}\left(V_{\mathcal{B}^{2} \mid B_{j^{1}} / K}\right), \text { for all } K \subset B_{j^{1}}, K \in \mathcal{B}^{2} \\
W_{B_{j^{1}}}\left(B_{j^{1}}\right)=\varphi_{B_{j^{1}}}(V)
\end{gathered}
$$

Thus, each party $B_{j^{2}} \subset B_{j^{1}}$ can obtain the amount $\varphi_{B_{j^{2}}}\left(W_{B_{j^{1}}}\right)$ which is the Shapley value of player $B_{j^{2}}$ in the subgame $W_{B_{j^{1}}}$.

To determine the division of the amount $\varphi_{B_{j^{2}}}\left(W_{B_{j^{1}}}\right)$ party $B_{j^{2}}$ receives, we define for all $H \subseteq B_{j^{2}}$ the restricted subgame $W_{B_{j^{1}} \mid B_{j^{2}} / H}$ as representing the subgame $W_{B_{j^{1}}}$ when $H$ replaces the party $B_{j^{2}}$ in $\mathcal{B}^{2}$. Then, a reasonable expectation for $H$ is the

\footnotetext{
${ }^{3}$ Proofs and the heuristic determinations of the LSV of theorems 2-6 are omitted. Details are avaible from the author upon request.
} 
Shapley value of player $H$ in this restricted subgame.

Thus, using the relative payoff of each subset $H$ of $B_{j^{2}}$, we can define the subgame $W_{B_{j^{2}}}$ on party $B_{j^{2}}$

$$
\begin{gathered}
W_{B_{j^{2}}}(\emptyset)=0 \\
W_{B_{j^{2}}}(H)=\varphi_{H}\left(W_{B_{j^{1}} \mid B_{j^{2}} / H}\right), \text { for all } H \subseteq B_{j^{2}}
\end{gathered}
$$

Finally, each player $i \in B_{j^{2}} \subset B_{j^{1}}$ can obtain the amount $\varphi_{i}\left(W_{B_{j^{2}}}\right)$, which is the Shapley value of player $i$ in the subgame $W_{B_{j^{2}}}$.

This bargaining procedure within coalitions can be characterized by the following axiom.

\section{Axiom 6"}

For all $K \subset B_{j^{1}}, K \in \mathcal{B}^{2}, W_{B_{j^{1}}}(K)=\varphi_{K}\left(V_{\mathcal{B}^{2} \mid B_{j^{1}} / K}\right)$ and $W_{B_{j^{1}}}\left(B_{j^{1}}\right)=\varphi_{B_{j^{1}}}(V)$

For all $H \subseteq B_{j^{2}}, B_{j^{2}} \subset B_{j^{1}}, W_{B_{j^{2}}}(H)=\varphi_{H}\left(W_{B_{j^{1}} \mid B_{j^{2}} / H}\right)$

This axiom implies that the characteristic function of the subgame $W_{B_{11}}$, is determined by giving to all $K \subseteq B_{j^{1}}$ the Shapley value of player $K$ in the game $V_{B^{2} \mid B_{1} / K}$ and to coalition $B_{j^{1}}$ the amount which the coalition receives, i.e as the Shapley value of player $B_{j^{1}}$ in the quotient game $V$. The characteristic function of the subgame $W_{B_{j^{2}}}$, is determined by giving to all $H \subseteq B_{j^{2}}$ the Shapley value of player $H$ in the restricted subgame $W_{B_{j^{1}} \mid B_{j^{2}} / H}$.

\section{Theorem 3}

There exists a unique LSV $\varphi^{2}$ satisfying axioms 1-5 and 6 " for side payments games with a strict LS B. It is given by

$$
\begin{aligned}
\varphi_{i}^{2}(U ; \mathbf{B})= & \sum_{\substack{H \subset B_{j}^{2} \\
i \notin H^{\prime}}} \sum_{\substack{G \subset B_{j}^{1} \\
B_{j}^{2} \notin G}} \sum_{\substack{F \subset M^{2} \\
B_{j}^{1} \notin F}} \delta_{h}\left(\left(b_{j}^{2}\right) \delta_{g}\left(n\left(B_{j}^{1}\right)\right) \delta_{f}\left(m^{2}-n\left(B_{j}^{1}\right)+1\right)\right. \\
& {[U(F \bigcup G \bigcup H \bigcup\{i\})-U(F \bigcup G \bigcup H)]+\frac{1}{n\left(B_{j}^{1}\right) b_{j}^{2}} } \\
& {\left[\sum_{\substack{S \subset M^{1} \\
B_{j}^{1} \notin S}} \delta_{s}\left(m^{1}\right)\left[U\left(S \bigcup B_{j}^{1}\right)-U(S)\right]-U\left(F \bigcup B_{j}^{1}\right)\right] }
\end{aligned}
$$

\section{Level structure values with a large quotient game}

The three LSV's we have developed in section 3 have the bargaining procedure among coalitions in common. Assuming the LS B, whatever the LSV used, the value of a coalition $B_{j^{1}}$ in the game $U$ is the same. This bargaining procedure among 
coalitions takes no notice of the possibility for a given coalition to form a new coalition with one or more of the parties belonging to the other coalitions. Actually, the bargaining procedure among coalitions we use takes into account the amount $U\left(B_{j^{1}}\right)$ which the coalition can obtain itself and the amounts $U\left(B_{j^{1}} \cup B_{q^{1}} \cup \ldots \cup B_{h^{1}}\right)$, but do not take into account the amounts $U\left(B_{j^{1}} \cup B_{q^{2}} \cup \ldots \cup B_{h^{2}}\right)$. Considering our example, this implies that coalitions $A$ and $B$ ignore that they are both composed of two parties. To integrate this information in the bargaining procedure among coalitions, we can define a game, which we will call a large quotient game, $V_{<\mathcal{B}^{2},\{T\}>}$, where $T$ is a subset of $\mathcal{B}^{1}$. This game is the formal representation of the bargaining procedure if the coalition $T$ and the parties $B_{j^{2}} \notin T$ have to divide the total gain among themselves. So, this large quotient game is defined assuming that the coalition strucure $<\mathcal{B}^{2},\{T\}>=\left\{B_{j^{2}}, \ldots, T, \ldots, B_{h^{2}}\right\}$ :

$$
V_{<\mathcal{B}^{2},\{T\}>}(S)=U\left(\bigcup_{B_{j^{2}} \in S} B_{j^{2}} \bigcup T\right) \text {, for all } S \in<\mathcal{B}^{2},\{T\}>
$$

Using this argument, we can calculate the Shapley value of each coalition $T \in \mathcal{B}^{1}$ in the large quotient game $V_{\left\langle B^{2},\{T\}\right\rangle}$, which represents the relative payoff of $T$. Then, due to the measure of the relative payoff of each $T \in \mathcal{B}^{1}$, we can define the quotient game $V$ which is the formal representation of the bargaining situation among coalitions $B_{j^{1}} \in \mathcal{B}^{1}$ :

$$
\begin{gathered}
V(\emptyset)=0 \\
V(S)=\varphi_{S}\left(V_{<\mathcal{B}^{2},\{S\}>}\right), \text { for all } S \in \mathcal{B}^{1} \\
V(N)=U(N)
\end{gathered}
$$

Then a reasonable expectation for coalition $B_{j^{1}} \in \mathcal{B}^{1}$ is the Shapley value of player $B_{j^{1}}$ in the quotient game $V$.

This bargaining procedure among coalitions can be characterized by the following axiom.

\section{Axiom 7}

For all $S \in \mathcal{B}^{1}, S \neq N, V(S)=\varphi_{S}\left(V_{<\mathcal{B}^{2},\{S\}>}\right)$ and $V(N)=U(N)$

This axiom simply specifies how the large quotient game $\left.V_{<\mathcal{B}^{2},\{S\}>}\right)$ is defined in order to calculate the relative payoff of each coalition $S \in \mathcal{B}^{1}$.

To determine the division of the amount the coalition $B_{j^{1}}$ receives we can use one of the three bargaining procedures within coalitions developed in section 3 . This yields the following results. 
Theorem 4

There exists a unique LSV $\varphi^{2}$ satisfying axioms 1-7 for side payments games with a strict LS B. It is given by

$$
\begin{aligned}
\varphi_{i}^{2}(U ; \mathbf{B})= & \sum_{\substack{H \subset B_{j}^{2} \\
i \notin H^{H}}} \delta_{h}\left(b_{j}^{2}\right)[U(H \bigcup\{i\})-U(H)]+\frac{1}{B_{j}^{2}}\left[\sum_{\substack{G \subset B_{j}^{1} \\
B_{j}^{2} \notin G}} \delta_{g}\left(n\left(B_{j}^{1}\right)\right)\right. \\
& {\left[U\left(G \bigcup B_{j}^{2}\right)-U(G)\right]-U\left(B_{j}^{2}\right)+\frac{1}{n\left(B_{j}^{1}\right)}\left[\sum_{\substack{S \subset M^{1} \\
B_{j}^{1} \notin S}} \delta_{s}\left(m^{1}\right)\right.} \\
& {\left[\sum_{\substack{F \subset M^{2} \\
S \bigcup B_{j}^{1} \notin F}} \delta_{f}\left(m^{2}-n\left(S \bigcup B_{j}^{1}\right)+1\right)\left[U\left(F \bigcup S \bigcup B_{j}^{1}\right)-U(F)\right]\right.} \\
& \left.\left.\left.-\sum_{\substack{F \subset M^{2} \\
S \notin F}} \delta_{f}\left(m^{2}-n(S)+1\right)[U(F \bigcup S)-U(F)]-U\left(B_{j}^{1}\right)\right]\right]\right]
\end{aligned}
$$

Theorem 5

There exists a unique LSV $\varphi^{2}$ satisfying axioms 1-5, 6' and 7 for side payments games with a strict LS B. It is given by

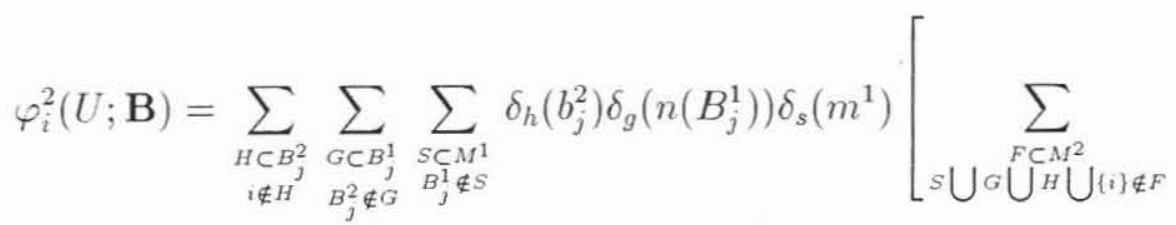

$$
\begin{aligned}
& \delta_{f}\left(m^{2}-n\left(S \bigcup B_{j}^{1}\right)+1\right)[U(F \bigcup S \bigcup G \bigcup H \bigcup\{i\})-U(F)] \\
& -\sum_{\substack{F \subset M^{2} \\
s \notin F, B_{j}^{1} \mid G \bigcup^{2} \bigcup\{i\}}} \delta_{f}\left(m^{2}-n(S)-n\left(B_{j}^{1}\right)+2\right)[U(F \bigcup S)-U(F)] \\
& -\sum_{\substack{F \subset M^{2} \\
S \bigcup G \bigcup_{H \notin F}}} \delta_{f}\left(m^{2}-n\left(S \bigcup B_{j}^{1}\right)+1\right)[U(F \bigcup S \bigcup G \bigcup H)-U(F)] \\
& \left.+\sum_{\substack{F \subset M^{2} \\
S \notin F, B_{j}^{1} \mid G \bigcup^{H}}} \delta_{f}\left(m^{2}-n(S)-n\left(B_{j}^{1}\right)+2\right)[U(F \bigcup S)-U(F)]\right]
\end{aligned}
$$




\section{Theorem 6}

There exists a unique LSV $\varphi^{2}$ satisfying axioms $1-5,6$ " and 7 for side payments games with a strict LS $\mathbf{B}$. It is given by

$$
\begin{aligned}
\varphi_{i}^{2}(U ; \mathbf{B})= & \sum_{\substack{H \subset B_{j}^{2} \\
i \notin H}} \sum_{\substack{G \subset B_{j}^{1} \\
B_{j}^{2} \notin G \in}} \sum_{\substack{F \in M^{2} \\
B_{j}^{1} \notin F}} \delta_{h}\left(b_{j}^{2}\right) \delta_{g}\left(n\left(B_{j}^{1}\right)\right) \delta_{f}\left(m^{2}-n\left(B_{j}^{1}\right)+1\right) \\
& {[U(F \bigcup G \bigcup H \bigcup\{i\})-U(F \bigcup G \bigcup H)]+\frac{1}{b_{j}^{2} n\left(B_{j}^{1}\right)} \sum_{\substack{S \subset M^{1} \\
B_{j}^{1} \notin S}} \delta_{s}\left(m^{1}\right) } \\
& {\left[\sum _ { T \subset M ^ { 2 } S \bigcup B _ { j } ^ { 1 } \notin T } \delta _ { t } \left(m^{2}-n\left(S \bigcup B_{j}^{1}+1\right)\left[U\left(T \bigcup S \bigcup B_{j}^{1}\right)-U(T)\right]\right.\right.} \\
& -\sum_{T \subset M^{2} S \notin T} \delta_{t}\left(m^{2}-n(S+1)[U(T \bigcup S)-U(T)]-U\left(F \bigcup B_{j}^{1}\right)\right]
\end{aligned}
$$

\section{Remarks and extensions}

We have obtained six values for games in which the players are already organized into a strict LS, which is a sequence of coalition structures. Each value allows an evaluation of the prospect that might arise as a result of playing a game when the players are organized into a strict LS. Moreover, each value is determined in a static framework. We ignore the problem of a dynamic process of formation of coalitions. This can be motivated by the existence of ideologic, social or other ties between players that allow us to decompose the society into a strict level structure. But the problem of the stability of a strict LS is still open.

We conclude this paper with two further remarks. When we compute the relative payoff of some players, we define a restricted game where $K_{1} \subset B_{j^{1}}$ replaces $B_{j^{1}}$. But we don't say anything about $K_{1}^{\prime}$, the complement of $K_{1}$ relative to $B_{j^{1}}$. Following Hart and Kurz (1983), we can introduce the following assumption. In defining the restricted game $V_{B_{21} / K_{1}}$, by replacing $B_{j^{1}}$ with $K_{1}$, we can assume that the members of $K_{1}^{\prime}$ stay together or will break apart into singletons. As a consequence, we have to study whether our values have always the same charaterization irrespective of the form of $K_{1}^{\prime}$. Put differently, we have to check if the level structure values have the property of consistency.

The final remark deals with axioms 6,6 , 6" and 7 . Those axioms allow us to determine the characteristic function of the subgames or quotient game which we have to define in order to compute the repartition among the coalitions and among the members of a coalition. In fact, we have defined a level structure value as the product of the Shapley values of the quotient game and the respective subgames. The question we have to answer is : how can we define thoses games? The answers proposed in this paper are entirely described by the four axioms mentioned above but one can easily propose another way to define the subgames and the resulting 
different level structure values. Intuitively, if we suppose that the players are already organized into a LS consisting out of three or more coalition structures, one can easily develop an hybrid level structure value.

\section{APPENDIX}

a) Heuristic determination of the LSV.

For all $i \in B_{j^{2}} \subset B_{j^{1}}$, we have :

$$
\varphi_{i}^{2}(U ; \mathbf{B})=\varphi_{i}\left(W_{B_{j^{2}}}\right)=\sum_{\substack{H \subset B_{j^{2}} \\ i \notin H}} \frac{h !\left(b_{j^{2}}-h-1\right) !}{b_{j^{2}} !}\left[W_{B_{j^{2}}}(H \bigcup\{i\})-W_{B_{j^{2}}}(H)\right]
$$

With the definition of the subgame $W_{B_{j^{2}}}$, we can write :

$$
\begin{aligned}
& W_{B_{j^{2}}}(H \bigcup\{i\})-W_{B_{j^{2}}}(H)=U(H \bigcup\{i\})-U(H) \text { if } H \bigcup\{i\} \subset B_{j^{2}} \\
& W_{B_{j^{2}}}(H \bigcup\{i\})-W_{B_{j^{2}}}(H)=\varphi_{B_{j^{2}}}\left(W_{B_{j^{1}}}\right)-U(H) \text { if } H \bigcup\{i\}=B_{j^{2}}
\end{aligned}
$$

Then, it follows that :

$$
\begin{aligned}
\varphi_{i}^{2}(U ; \mathbf{B})= & \sum_{\substack{H \subset B_{j}^{2} \\
i \notin H,}} \delta_{h}\left(b_{j}^{2}\right)[U(H \bigcup\{i\})-U(H)] \\
& +\frac{1}{b_{j}^{2}}\left[\varphi_{B_{j}^{2}}\left(W_{B_{j}^{1}}\right)-U\left(B_{j}^{2}\right)\right]
\end{aligned}
$$

but,

$$
\varphi_{B_{j^{2}}}\left(W_{B_{j^{1}}}\right)=\sum_{\substack{K \in B_{j^{1}} \\ B_{j^{2}} \notin K}} \frac{k !\left[n\left(B_{j^{1}}\right)-k-1\right] !}{n\left(B_{j^{1}}\right) !}\left[W_{B_{j^{1}}}\left(K \bigcup B_{j^{2}}\right)-W_{B_{j^{2}}}(K)\right]
$$

and the definition of the subgame $W_{B_{j^{1}}}$, implies that:

$$
\begin{aligned}
& W_{B_{j^{1}}}\left(K \bigcup B_{j^{2}}\right)-W_{B_{j^{1}}}(K)=U\left(K \bigcup B_{j^{2}}\right)-U(K) \text { if } K \bigcup B_{j^{2}} \subset B_{j^{1}} \\
& W_{B_{j^{1}}}\left(K \bigcup B_{j^{2}}\right)-W_{B_{j^{1}}}(K)=\varphi_{B_{j^{1}}}(V)-U(K) \quad \text { if } K \bigcup B_{j^{2}}=B_{j^{1}}
\end{aligned}
$$

So we can deduce that:

$$
\begin{aligned}
\varphi_{B_{j}^{2}}\left(W_{B_{j}^{1}}\right)= & \sum_{\substack{G \subset B_{j}^{1} \\
B_{j}^{2} \notin G}} \delta_{g}\left(n\left(B_{j}^{1}\right)\right)\left[U\left(G \bigcup B_{j}^{2}\right)-U(G)\right] \\
& +\frac{1}{n\left(B_{j}^{1}\right)}\left[\varphi_{B_{j}^{1}}(V)-U\left(B_{j}^{1}\right)\right]
\end{aligned}
$$


Finally, we have :

$$
\varphi_{B_{j^{1}}}(V)=\sum_{\substack{S \subset M^{1} \\ B_{j 1} \notin S}} \frac{s !\left(m^{1}-s-1\right) !}{m^{1} !}\left[V\left(S \bigcup B_{j^{1}}\right)-V(S)\right]
$$

Then assuming the LS B, with equations (1.2), (1.3), (1.4) and (1.5), we can deduce that the LSV of player $i \in B_{j^{2}} \subset B_{j^{1}}$ is :

$$
\begin{aligned}
\varphi_{i}^{2}(U ; \mathbf{B})= & \sum_{\substack{H \subset B_{j}^{2} \\
i \notin H}} \delta_{h}\left(b_{j}^{2}\right)[U(H \bigcup\{i\})-U(H)]+\frac{1}{b_{j}^{2}} \\
& {\left[\sum_{\substack{G \subset B_{j}^{1} \\
B_{j}^{2} \notin G}} \delta_{g}\left(n\left(B_{j}^{1}\right)\right)\left[U\left(G \bigcup B_{j}^{2}\right)-U(G)\right]-U\left(B_{j}^{2}\right)\right.} \\
& \left.+\frac{1}{n\left(B_{j}^{1}\right)}\left[\sum_{\substack{S \subset M^{1} \\
B_{j}^{1} \notin S}} \delta_{s}\left(m^{1}\right)\left[U\left(S \bigcup B_{j}^{1}\right)-U(S)\right]-U\left(B_{j}^{1}\right)\right]\right]
\end{aligned}
$$

b) Proof of theorem 1

Axioms 1-6 are trivially satisfied by the LSV value. To see that $\varphi^{2}$ is the only value which satisfies the six axioms, we note that any game can be written as a linear combination of games of the form $U_{R}$, where :

$$
U_{R}(S)= \begin{cases}1 & \text { if } R \subset S \\ 0 & \text { if } R \not \subset S\end{cases}
$$

For the game $U_{R}$ and the partition $\mathcal{B}^{1}=\left\{B_{1^{1}}, \ldots, B_{m^{1}}\right\}$, we define

$$
R_{1}^{\prime}=\left\{j \mid B_{j^{1}} \bigcap R \neq \oslash\right\}
$$

Then $V=U / \mathcal{B}^{1}$ has the form

$$
V(T)= \begin{cases}1 & \text { if } R_{1}^{\prime} \subset T \\ 0 & \text { if } R_{1}^{\prime} \not \subset T\end{cases}
$$

Thus $\mathrm{V}$ is the symmetric game $U_{R}$, which has the carrier $R_{1}^{\prime}$, and by Axioms 1,2 , 3 and 4 we must have

$$
\sum_{i \in B_{j^{1}}} \varphi_{i}^{2}\left(U_{R}\right)=\left\{\begin{array}{cc}
\frac{1}{r_{1}^{\prime}} & \text { if } j \in R^{\prime} \\
0 & \text { if } j \notin R^{\prime}
\end{array}\right.
$$


so $\sum_{i \in B_{j 1}} \varphi_{i}^{2}\left(U_{R}\right)$ is unique.

Hence, by axiom 6 , the subgame $W_{B_{j^{1}}}$ defined on coalition $B_{j^{1}}$ is uniquely determined, and we have :

$$
W_{B_{j^{1}}}(X)=\left\{\begin{array}{c}
U_{R}(X), \text { for all } X \subset B_{j^{1}} \\
\frac{1}{r^{\prime}}, \text { if } X=B_{j^{1}}
\end{array}\right.
$$

Then, we can deduce that $\varphi_{B_{j^{2}}}\left(W_{B_{j^{1}}}\right)=\sum_{i \in B_{j^{2}}} \varphi_{i}^{2}\left(U_{R}\right)$ is uniquely determined, and so, by axiom 6 , the subgame $W_{B_{j^{2}}}$ defined on the party $B_{j^{2}}$ too.

Hence, we have :

$$
W_{B_{j^{2}}}(T)=\left\{\begin{array}{l}
U_{R}(T), \text { for all } T \subset B_{j^{2}} \\
\varphi_{B_{j^{2}}}\left(W_{B_{j^{1}}}\right), \text { if } T=B_{j^{1}}
\end{array}\right.
$$

Finally, we can assert that $\varphi_{i}^{2}\left(U_{R}\right)=\varphi_{i}\left(W_{B_{2}}\right)$ is uniquely determined.

Thus, our axioms 1, 2, 3, 4 and 6 uniquely determine a LSV for a game of the form $U_{R}$, and for multiples of these, with a strict LS. Axiome 5, together with the fact that these $U_{R}$ form a basis for the game space, guarantees the uniqueness for all games.

\section{REFERENCES}

Hart.S and Kurz.M (1983), Endogenous formation of coalitions, Econometrica 57, pp 589-614

Owen.G (1977), Values of games with a priori unions, Essays in mathematical economics and game theory, ed. by Hein.R and Moeschlin.O, NY Springer Verlag, pp $76-88$

Shapley.L.S (1953), A value for n-person games, in contributions to the theory of games, Vol.II, ed. Kuhn.H.W and Tucker.A.W, Princeton University Press, pp 307317

Winter.E (1989), A value for cooperative games with levels structure of cooperation, International Journal of Game Theory 18, pp 227-240. 


\section{LES CAHIERS DE GRIGNON}

1992 - 1998

N 92/01 Hémidy, L. ; Soler, L.G.

Conseil et aide à la décision en agriculture : quelles recherches en gestion développer?

$\mathrm{N}^{\circ} \mathbf{9 2 / 0 2}$ Réquillart, V. ;Giraud-Héraud, E.

Différenciation des produits sur le marché des édulcorants : un modèle d'analyse.

$\mathrm{N}^{\circ}$ 92/03 Jayet, P.A.

Instruments de la PAC et analyse de bien-être : politiques de prix et taxes ou subventions.

$\mathrm{N}^{\circ}$ 92/04 Bourgeon, J.M. ;Jayet, P.A.

Price and set-aside policies for agriculture an approach through the incentive theory.

N ${ }^{\circ}$ 92/05 Jayet, P.A. ;Le Roux, Y.

Short term effects of the CAP reform in France and in the United Kingdom : ome results for intra-EC strategy.

$\mathrm{N}^{\circ}$ 92/06 Giraud-Héraud, E. ;Réquillart, V.

Concurrence potentielle avec différenciation verticale des produits. L'exemple du marché du sucre dans la CEE

$\mathrm{N}^{\circ}$ 92/07 Réquillart, V. ;Giraud-Héraud, E.

Imperfect competition on the european sweetener market.

$\mathrm{N}^{\circ}$ 92/08 Ball, E. ;Bureau, J.C. ;Butault, J.P. ;Witzke, H.P.

The stock of capital in European Community agriculture.

$\mathrm{N}^{\circ}$ 92/09 Bureau, J.C.

The choice of an index number for international comparisons.

N 93/01 Réquillart, V. ;Cabolis, C. ;Giraud-Héraud, E.

Welfare effects of HFCS development in the US sweetner market.

$\mathrm{N}^{\circ}$ 93/02 Barkaoui, A. ;Bureau, J.C.

Nombres indices et fonctions de distance : application à la mesure de la productivité de la branche agricole.

$\mathrm{N}^{\circ}$ 93/03 Bureau, J.C.

La mesure du soutien public à la production dans l'agriculture communautaire.

No 93/04 Carles, R. ;Chitrit, J.J. ;Millet, G.

Marges et coûts de production du blé tendre en Ile-de-France. Les effets de la nouvelle PAC.

$\mathbf{N}^{\circ}$ 93/05 Giraud-Héraud, E. ;Hammoudi, A.

On the incentive for product proliferation in a differentiated market. 
N ${ }^{\circ}$ 93/06 Hémidy, L. ;Maxime, F. ;Soler, L.G.

Instrumentation et pilotage stratégique dans la petite entreprise. Le cas de l'entreprise agricole.

$\mathrm{N}^{\circ}$ 93/07 Bourgeon, J.M. ;Le Roux, Y.

Optimal auction theory and EC grain exports.

$\mathbf{N}^{\circ}$ 93/08 Jayet, P.A.

Revenus et politiques agricoles, efficacité et équité : un modèle pour des réponses quantifiées.

$\mathrm{N}^{\circ}$ 93/09 Le Roux, Y.

Modelling of agricultural markets and econometrics of disequilibrium. A review of some applications to markets with minimum prices and to export models.

$\mathbf{N}^{\circ}$ 93/10 Jayet, P.A. ; Hofstetter A.

An application of linear programming to model the impacts on agricultural supply and income of the new CAP reforms.

$\mathrm{N}^{\circ}$ 93/11 Bourgeon, J.M. ;Le Roux, Y.

Adjudications de restitutions à l'exportation de céréales européennes une application de l'économie des enchères.

$\mathrm{N}^{\circ}$ 93/12 Jayet, P.A. ;Le Roux, Y.

Politique Agricole Commune et décisions publiques : des principes à l'épreuve des comportements stratégiques.

N 93/13 Giraud-Héraud, E. ;Le Mouël C. ;Réquillart, V.

Réforme céréalière européenne et marché mondial du Corn Gluten Feed.

Quelles stratégies pour les Etats-Unis?

$\mathrm{N}^{\circ}$ 93/14 Bourgeon, J.M. ;Jayet, P.A.

Politique Agricole Commune : une approche incitative du gel des terres.

$\mathbf{N}^{\circ}$ 94/01 Barkaoui, A. ;Bureau, J.C. ;Butault, J.P.

Les comparaisons internationales de prix, volume et productivité. Méthodes et application à la branche agriculture.

$\mathrm{N}^{\circ}$ 94/02 Ball, V.E. ;Bureau, J.C. ;Eakin, K. ;Somwaru, A.

A supply-response framework with acreage restrictions for modelling european agriculture under the new CAP conditions.

$\mathrm{N}^{\circ}$ 94/03 Bontems, P. ;Bourgeon,J.M.

Régulation par la production ou par l'intrant : quelques résultats.

N 94/04 Giraud-Héraud, E. ;Jayet, P.A. ;Le Roux, Y.

Politique Agricole Commune et stratégie des Etats-membres : coopération et intégration.

$\mathrm{N}^{\circ}$ 94/05 Costa, S. ;Réquillart, V.

Economic Impacts of a Biofuel Project in France and in the E.U.

$\mathrm{N}^{\circ}$ 94/06 Bontems, P.

Incentives and the Regulation of Non-Point Source Pollution. 
N 95/01 Carles, R. ;Codet, C. ;Millet, G.

Deux notes sur les exploitations de grande culture Les producteurs de céréales en France et leurs performances : rendements, coûts, revenus. Le pois protéagineux : quelles perspectives économiques pour les producteurs?

$\mathrm{N}^{\circ}$ 95/02 Marette, $\mathrm{S}$.

Prix Négocié et Prix Affiché avec Anti-Sélection.

$\mathrm{N}^{\circ}$ 95/03 Bontems, P.;Jayet, P.A.

Régulation multi-facteurs : gel de terre et mesures agri-environnementales.

N ${ }^{\circ}$ 95/04 Giraud-Héraud, E.;Hammoudi, H.

Formation des cartels : Concepts et application à la différenciation spatiale.

N ${ }^{\circ}$ 95/05 Giraud-Héraud, E.;Jayet, P.A.;Le Roux, Y.;Mathurin, J.

Coordination dans l'instrumentation de la PAC : Une approche par la théorie du Coeur.

$N^{\circ}$ 96/01 Coestier, B.;Marette, $S$.

On multiple equilibria in markets with adverse selection.

$\mathrm{N}^{\circ} \mathbf{9 6 / 0 2}$ Marette, $\mathrm{S}$.

Bargaining versus price competition under adverse selection.

$\mathrm{N}^{\circ}$ 96/03 Jayet, P.A.;Mathurin, J.

Régulation viticole et coordination dans l'Union européenne.

$\mathbf{N}^{\circ}$ 96/04 Jayet, P.A.;Birfet, A.;Hofstetter, A.

Forêt paysanne et Politique Agricole Commune : une évaluation des impacts d'une incitation au reboisement.

$\mathrm{N}^{\circ}$ 96/05 Lefaudeux, F.;Mathurin, J.

Prise de décision au sein d'organisations internationales : le cas de l'Union européenne.

$\mathbf{N}^{\circ}$ 97/01 Marette, $S$.

Buyers' endogeneous choice and adverse selection.

$\mathbf{N}^{\circ} \mathbf{9 7 / 0 2}$ Chantreuil, M.;Mathurin, J.

Implementation of a production control program within the European Union : a cooperative games approach.

$\mathbf{N}^{\circ}$ 97/03 Schiavina, A.

Accords commerciaux en présence de différentiation des produits.

N97/04 Bureau, J.C.;de Fontguyon, G.;Marette, S.;Schiavina, A. Qualité des produits et commerce international : l'exemple du conflit entre l'Europe et les Etats-Unis sur la viande bovine.

$\mathbf{N}^{\circ} \mathbf{9 7 / 0 5}$ Jayet, P.A.;Mathurin, J.; Hofstetter, A.

Un modèle de simulation des échanges viticoles dans l'Union européenne.

N⿳97/06 Chantreuil, F.;Trannoy, A.

Inequality decomposition values. 
$\mathbf{N}^{\circ}$ 97/07 Marette, S.

Intermédiation et affichage des prix dans un contexte d'anti-sélection.

N97/08 Giraud-Héraud, E.

Pour ou contre la vente de vin en primeur?

$N^{\circ}$ 98/01 Chantreuil, F.

Axiomatics of level structure values. 